\title{
Multiple sclerosis has a distinct lipid signature in plasma and cerebrospinal fluid
}

\author{
Esclerose múltipla tem uma assinatura lipídica distinta no plasma e no líquido cefalorraquiano \\ Enedina Maria Lobato de OLIVEIRA', Daniela Antunes MONTANI², Diogo OLIVEIRA-SILVA², André Filipe \\ RODRIGUES-OLIVEIRA ${ }^{3}$, Sandro Luiz de Andrade MATAS ${ }^{1}$, Gustavo Bruniera Peres FERNANDES ${ }^{4}$, Ismael \\ Dale Cotrim Guerreiro da SILVA5, Edson Guimarães LO TURCO²
}

\begin{abstract}
The diagnosis of multiple sclerosis (MS) has changed over the last decade, but remains a composite of clinical assessment and magnetic resonance imaging to prove dissemination of lesions in time and space. The intrathecal synthesis of immunoglobulin may be a nonspecific marker and there are no plasma biomarkers that are useful in the diagnosis of MS, presenting additional challenges to their early detection. Methods: We performed a preliminary untargeted qualitative lipidomics mass spectrometry analysis, comparing cerebrospinal fluid (CSF) and plasma samples from patients with MS, other inflammatory neurological diseases and idiopathic intracranial hypertension. Results: Lipid identification revealed that fatty acids and sphingolipids were the most abundant classes of lipids in the CSF and that glycerolipids and fatty acids were the main class of lipids in the plasma of patients with MS. The area under the curve was 0.995 (0.912-1) and 0.78 (0.583-0.917), respectively. The permutation test indicated that this ion combination was useful for distinguishing MS from other inflammatory diseases ( $p<0.001$ and 0.055 , respectively). Conclusion: This study concluded that the CSF and plasma from patients with MS bear a unique lipid signature that can be useful as a diagnostic biomarker.
\end{abstract}

Keywords: Biomarkers; plasma; cerebrospinal fluid; lipids; multiple sclerosis; myelin sheath

\begin{abstract}
RESUMO
Embora o diagnóstico da EM tenha se modificado na última década, ainda tem como requisito básico a demonstração da disseminação no tempo e no espaço, através do quadro clínico e do exame de ressonância magnética. A síntese intratecal de imunoglobulina pode ser um marcador inespecífico e não há biomarcadores plasmáticos que sejam úteis no diagnóstico da EM, impondo desafios à sua detecção precoce. Métodos: Realizamos uma análise lipidômica preliminar por espectrometria de massas, não direcionada, qualitativa, comparando amostras de LCR e plasma de pacientes com EM, outras doenças neurológicas inflamatórias e hipertensão intracraniana idiopática (HII). Resultados: A identificação lipídica revelou que os ácidos graxos e esfingolipídios foram as classes mais abundantes de lipídios no LCR e que glicerolipídios e ácidos graxos foram a principal classe de lipídios no plasma de pacientes com EM. A AUC foi de 0,995 (0,912-1) e 0,78 (0,583-0,917), respectivamente. 0 teste de permutação indicou que essa combinação de íons foi útil para distinguir a EM de outras doenças inflamatórias ( $p<0,001$ e 0,055, respectivamente). Conclusão: Este estudo sugere que o líquido cefalorraquidiano (LCR) e o plasma de pacientes com EM possuem uma assinatura lipídica única, pode ser útil como um biomarcador diagnóstico.
\end{abstract}

Palavras-chave: Biomarcadores; plasma; líquido cefalorraquidino; lipídeos; esclerose múltipla; bainha de mielina

\footnotetext{
Universidade Federal de São Paulo, Departamento de Neurologia e Neurocirurgia Disciplina de Neurologia, São Paulo SP, Brasil;

${ }^{2}$ Universidade Federal de São Paulo, Centro de Pesquisa em Urologia, Departamento de Cirurgia. Disciplina de Urologia, São Paulo SP, Brasil;

${ }^{3}$ Universidade Federal de São Paulo, Instituto de Ciências Ambientais, Químicas e Farmacêuticas, Departamento de Química, São Paulo SP, Brasil;

«Universidade Federal de São Paulo, Departamento de Psicobiologia, Disciplina de Psicobiologia, São Paulo SP, Brasil;

${ }_{5}^{5}$ niversidade Federal de São Paulo, Laboratório de Ginecologia Molecular, Departamento de Ginecologia e Obstetrícia, São Paulo SP, Brasil.
}

Enedina Maria Lobato de Oliveira（iD https://orcid.org/0000-0002-4939-7200; Daniela Antunes Montani iD https://orcid.org/0000-0002-0637-6848; Diogo Oliveira-Silva (iD https://orcid.org/0000-0002-0046-3502; André Filipe Rodrigues-Oliveira iD https://orcid.org/0000-0002-5279-4012; Sandro Luiz de Andrade Matas ID https://orcid.org/0000-0002-0479-2450; Gustavo Bruniera Peres Fernandes iD https://orcid.org/0000-0002-4459-5179; Ismael Dale Cotrim Guerreiro da Silva (iD) https://orcid.org/0000-0002-1328-233X; Edson Guimarães Lo Turco (iD) https://orcid.org/0000-0002-3509-847X Correspondence: Enedina Maria Lobato de Oliveira; Departamento de Neurologia da UNIFESP; Rua Botucatu, 740; 04023-900 São Paulo SP, Brasil; E-mail:enedina.oliveira@unifesp.br

Support and Conflict of Interest: It is important to highlight that this work was supported by an unrestricted research grant from Novartis Brazil. Neither Novartis Brazil nor its employees participated or influenced samples and data collection, results and statistical analyses. Novartis Brazil or its employees were not responsible for manuscript preparation and submission. None of the authors have worked or are currently working for Novartis Brazil.

Disclosures: Enedina Maria Lobato de Oliveira has received speaker fee and consultant honoraria from Merck, Teva, Biogen, Sanofi-Genzyme, and Roche, and travel expenses for scientific meetings sponsored by Merck. Daniela Antunes Montani, Diogo Oliveira-Silva, André Filipe Rodrigues-Oliveira, Sandro Luiz de Andrade Mattas, Gustavo Bruniera Peres Fernandes, Ismael Dale Cotrim Guerreiro da Silva and Edson Guimarães Lo Turco have nothing to disclose. Received 12 April 2019; Received in final form 24 May 2019; Accepted 17 June 2019. 
Multiple sclerosis (MS) is a complex inflammatory autoimmune demyelinating disease of the central nervous system (CNS), resulting from environmental and genetic interactions. It is the leading cause of permanent nontraumatic disability in young adults ${ }^{1}$. Its diagnosis has changed over the last decade but still remains a composite of clinical evaluation and magnetic resonance imaging (MRI) requirements to prove dissemination in time and space, reflecting the multitude of brain lesions appearing at different moments ${ }^{2}$.

To date, markers of intrathecal immunoglobulin synthesis, such as oligoclonal bands or the immunoglobulin $\mathrm{G}$ index have been used as diagnostic and/or prognostic tools, but they lack specificity. Also, there has been no plasma biomarker that is a useful tool in MS diagnosis. This somewhat limited scenario imposes some challenges to earlier MS detection $^{3,4}$. An MRI is the only surrogate marker, but it provides indirect and limited information about the disease and its pathophysiological process.

The cerebrospinal fluid (CSF) remains a potential source when looking for a disease biomarker in MS. It is in close contact with the brain and the blood-brain barrier and it is conceivable that the inflammation and the cellular damage intrinsic to the multistep process of MS pathology may be detectable in $\mathrm{CSF}^{5}$. Recent studies have shown that the CSF levels of myo-inositol were discriminatory between patients with MS and other neurological diseases and that chitinase-3 levels were predictive of a new relapse and new gadoliniumenhancing lesions ${ }^{6,7}$.

In addition, there is a growing body of evidence of the importance of lipids in the pathophysiology of different CNS diseases ${ }^{8,9}$. Indeed, lipids represent a broad group of molecules with critical roles in cell biology and inflammation and are present at a high concentration in brain tissue $^{10}$. Accordingly, lipidomics analyses of the CSF in patients with MS show an increase in molecules associated with oxidative stress and lipid degradation, which may be responsible for the maintenance of the autoimmune process ${ }^{11}$. Moreover, patients with MS have a higher level of ceramide in the CSF, which may be linked to the axonal damage observed in the disease ${ }^{12}$. Ceramide is produced in the CSF through the hydrolysis of sphingomyelin. Curiously, a recently published paper demonstrated that the sphingomyelinase activity is elevated in the CSF of patients with $\mathrm{MS}^{13}$.

Although the CSF seems the logical fluid to study, one must consider the difficulties in obtaining it. Therefore, a useful biomarker that can be found in plasma is of utmost importance. Several studies have demonstrated that plasma from patients with MS exhibits biochemical profiles distinguishable from other neurological diseases ${ }^{14,15}$. Recently, it has been shown that the presence of sphingomyelin and lysophosphatidylethanolamine differentiated patients with MS from healthy controls ${ }^{16}$. Additionally, the patients displayed metabolites related to oxidative stress ${ }^{17}$.

This study aimed to evaluate a lipid profile unique to MS, present in CSF and plasma. Its identification could complement current diagnostic criteria, improve patient care, and guide therapeutic decisions.

\section{METHODS}

\section{Study design}

We performed a preliminary untargeted qualitative lipidomics analysis comparing CSF and plasma samples from patients with MS, other inflammatory neurological diseases (OIND), and idiopathic intracranial hypertension (IIH). Initially, to investigate whether inflammatory diseases have a specific lipid profile, we clustered the CSF samples from patients with MS and OIND to form an inflammatory group and compared those with the CSF samples from patients with IIH, the noninflammatory control group. In addition, to identify a unique MS signature, we compared CSF and plasma samples from both MS and OIND patients, as separate groups. The institutional ethics committee approved the study (CAEE: 39862114.0.0000.5505/951.893) and participants provided written informed consent.

\section{The CSF and plasma samples}

Cerebrospinal fluid and plasma samples, frozen and stored at $-80^{\circ} \mathrm{C}$, collected between 2014 to 2015, were used for the experiments carried out at the Institute of Environmental, Chemistry and Pharmaceutical Sciences, Universidade Federal de São Paulo, between July and December 2016. The CSF was obtained as part of the routine clinical investigation, according to the assistant physician's best judgment, from patients with neurological diseases who were followed at the Neurology Department. When appropriate, a nonfasting blood sample was drawn at the same time as the CSF collection, in order to detect oligoclonal bands by isoelectric focusing, according to standard protocol. After the routine CSF examination and oligoclonal band testing, the remaining CSF and plasma samples were stored for later use, in the experiments described below. There were 42 paired CSF plasma samples from patients with either MS or OIND, and 15 CSF control samples collected from patients with IIH, totaling 57 samples.

All the patients signed a form authorizing the collection of CSF by lumbar puncture, as part of a routine clinical investigation.

\section{Clinical data}

We obtained data on the final diagnosis, clinical characteristics and CSF abnormalities by reviewing the patients' medical records. The CSF examination for routine clinical 
diagnosis included global and differential cytology analysis, routine biochemical immunological and microbiological analyses.

\section{Lipid extraction}

The lipids were extracted based on the Bligh and Dyer protocol with minor modifications ${ }^{18}$. Briefly, $50 \mu \mathrm{L}$ of the CSF and plasma sample were placed in a microtube with $125 \mu \mathrm{L}$ chloroform, $250 \mu \mathrm{L}$ methanol and $50 \mu \mathrm{L}$ distilled water. This mixture was vortexed for one minute. Then, $100 \mu \mathrm{L}$ water and $125 \mu \mathrm{L}$ chloroform were added and centrifuged at $500 \times g$ for five minutes resulting three phases. The upper phase containing the lipids was recovered and transferred to another microtube, which was left open overnight at room temperature for solvent evaporation.

\section{Liquid chromatography-electrospray ionisation mass spectrometry and data processing}

The analyses were performed with the ultra fast liquid chromatography system (Shimadzu, Kyoto, Japan), using a C18 column, coupled with a Bruker ESI-micrOTOFQII mass spectrometer (Billerica, MA, USA). Direct injection was performed using a liquid chromatography system. The mobile phase used was isopropanol/acetonitrile $(1: 1, \mathrm{v} / \mathrm{v})$ and $10 \mathrm{mmol} / \mathrm{L}$ of ammonium acetate with a flow of $200 \mu \mathrm{L} /$ minute. The spectra were obtained in an Apollo ion source according to the following parameters: $2.0 \mathrm{bar}$ nebulizer gas, dry gas of $8.0 \mathrm{~L} /$ minute, the temperature of $180^{\circ} \mathrm{C}$ and voltage of $4.5 \mathrm{kV}$. The mass $/$ charge ratio $(\mathrm{m} / \mathrm{z})$ was detected in scan (100-1200 Da) in positive mode. Sodium formate (Sigma-Aldrich) with a range of $\mathrm{m} / \mathrm{z}$ 50-1200 was used as the calibration standard.

The acquired spectra were recalibrated in DataAnalysis 4.1 (Billerica, MA, USA) and a list of ions $(\mathrm{m} / \mathrm{z}$ ) and their respective intensities were extracted from each spectrum. The lists containing the ions and their intensities, already separated by group (MS, OIND, and IIH), were processed through the MetaboAnalyst 3.0 online software (www.metaboanalyst.ca) so that the set of ions of each sample was combined generating a single table. For the processing of these data, a mass error of $\mathrm{m} / \mathrm{z} 0.05$ was used as tolerance parameter.

\section{Statistical analysis}

The table generated after the processing of the individual peaks was used to carry out the multivariate analysis of the data. For this, we used the MetaboAnalyst 3.0 online software. A principal component analysis and a partial least squares discriminant analysis (PLS-DA) were performed on the logtransformed data and standardized by auto-scaling. The principal component analysis was used to observe grouping and the samples discrepancies in general, while the PLS-DA was used to maximize the variations and to guarantee the discriminatory effect of the components based on the values of the variable importance in projection (VIP).
A cross-validation test was applied to validate the method created by PLS-DA and indicated which component of the model was the one that best explained the variations of ions between the groups. Based on the PLS-DA, we selected the ions with the highest VIP score, from the component with the greatest discriminatory effect, as potential biomarkers, according to the adducts and mass tolerance of $0,05 \mathrm{~m} / \mathrm{z}$. Those ions that were hyper-represented in the MS group were valued according to their VIP-PLS score. We built a ROC curve for each ion and for their combination. In addition, we performed a permutation test (1000x) and a prediction class probability based on our samples.

The ions selected as potential biomarkers were identified by the online database LipidMaps (www.lipidmaps.org). The identification was performed considering the $\mathrm{H}^{+}, \mathrm{Na}^{+}, \mathrm{K}^{+}$and $\mathrm{NH}_{4}^{+}$ions in the positive ionization mode. Compounds with a maximum error of $0.05 \mathrm{~m} / \mathrm{z}$ were considered.

\section{RESULTS}

\section{Clinical characteristics}

The clinical data are summarized in Table 1. Briefly, there were 13 patients with multiple sclerosis, eight with OIND, and 15 with idiopathic intracranial hypertension. The mean age of the entire population was 38 years $( \pm 12.9)$. However, patients with MS were slightly younger (35 \pm 10.3 years) than the IIH group. The female-to-male ratio varied from 2.5-4:1. Patients with MS were distributed as follows: two patients (15\%) with primary progressive and 11 (85\%) with relapsing-remitting MS. The MS group had had at least one relapse before CSF collection and the most common symptom was an acute partial myelitis. Regarding neurological disability, patients with MS were mildly impaired with a median Expanded Disability Status Scale score of 2.5.

The OIND group was heterogeneous and comprised patients with demyelinating, inflammatory, and vascular diseases. The patients with a demyelinating nonMS disease had neuromyelitis optica or idiopathic optic neuritis. The remaining patients with an inflammatory or vascular disease had a final diagnosis of Susac syndrome, rhombencephalitis, Vogt-Koyanagi-Harada, and embolic stroke.

The CSF and plasma samples were collected within 15 days of an acute exacerbation in 7 (53.8\%) and 4 (50\%) patients of the MS and OIND groups, respectively. The CSF from patients with IIH was normal, whereas patients with an OIND showed a more inflammatory pattern with an average of 18 cells/ml ( \pm 29$)$, predominantly lymphocytes, and higher levels of CSF protein (51.3 \pm 30.7$)$. Cerebrospinal fluid oligoclonal bands were present in 11 patients with MS. One patient was not tested for oligoclonal bands. 
Table 1. Demographics, clinical and CSF characteristics of the three patient groups.

\begin{tabular}{|c|c|c|c|}
\hline Variables & MS & OIND & $\mathrm{IIH}$ \\
\hline N & 13 & 8 & 14 \\
\hline PPMS (n, \%) & $2(15 \%)$ & $(-)$ & $(-)$ \\
\hline NMO $(n, \%)$ & $(-)$ & $2(25 \%)$ & $(-)$ \\
\hline Gender (\%) & $F(79 \%)$ & $F(62,5 \%)$ & $F(78 \%)$ \\
\hline $\mathrm{F} / \mathrm{M}$ & $4 \mathrm{~F}: 1 \mathrm{M}$ & $2.5 \mathrm{~F}: 1 \mathrm{M}$ & 4F:1M \\
\hline Age (mean, SD) & $35( \pm 10.3)$ & $38.6( \pm 15.5)$ & $41( \pm 13.2)$ \\
\hline \multicolumn{4}{|l|}{ Disease duration, y (mean, SD) } \\
\hline up to CSF & $5.2( \pm 7.7)$ & $3.1( \pm 6)$ & $2.3( \pm 1.7)$ \\
\hline Total time & $6.9( \pm 7.8)$ & $4.9( \pm 6.1)$ & $2.3( \pm 1.7)$ \\
\hline Follow up time, y & $2.8( \pm 4)$ & $1.6( \pm 1.4)$ & N/A \\
\hline Relapses up to CSF collection (mean, sd) & $1.5( \pm 1.5)$ & $1.4( \pm 0.7)$ & N/A \\
\hline \multicolumn{4}{|l|}{ First symptom (n, \%) } \\
\hline ADEM like & 1 & 0 & N/A \\
\hline Cerebellar & 1 & 0 & N/A \\
\hline Myelitis & 8 & 1 & N/A \\
\hline Brain stem & 1 & 4 & N/A \\
\hline Optic neuritis & 2 & 3 & N/A \\
\hline \multicolumn{4}{|l|}{ CSF } \\
\hline Collected during relapse (n, \%) & $5 / 13(38.5 \%)$ & $4 / 8(50 \%)$ & NA \\
\hline Cell count (mean, sd) & $5.4( \pm 6.3)$ & $18.3( \pm 29)$ & $1( \pm 0.85)$ \\
\hline Total protein level, mg/dL, (mean, sd) & $30.8( \pm 12)$. & $51.3( \pm 30.7)$ & $29( \pm 12.8)$ \\
\hline OCB positive (n, \%) & $11 / 12(91.6 \%)$ & $1 / 8(12.5 \%)$ & NA \\
\hline
\end{tabular}

\section{Lipidomics analysis}

We processed the data from the acquired spectra and generated a table containing 733 ions and identified those that were present in at least $50 \%$ of the samples (Table 2).

\section{CSF - Inflammation versus noninflammation}

To investigate whether inflammatory diseases would have a distinct profile, we compared IIH with MS and OIND. In these groups, the PLS-DA analysis suggested that component 4 of this model was the one that best explained the variations of ions between the samples. Figure 1A shows the group of 15 VIP ions with the greatest discriminatory PLS-DA score. Lipid identification revealed that fatty acids and polyketides were the main class of lipids in the inflammatory signature (Table 2). The area under the curve (AUC) for the inflammatory signature was 0.704 (0.205-0.927) and the p-value for the permutation test, was 0.086 (Figure $1 \mathrm{~B}$ and $1 \mathrm{C}$ ).

\section{CSF - MS versus IIH}

Additionally, to explore the existence of a disease-specific lipid pattern, we compared MS with IIH. The PLS-DA analysis suggested that component 4 of this model was the one that best explained the variations of ions between the groups. Figure 2A shows the group of 15 VIP ions with the greatest discriminatory PLS-DA score. Lipid identification revealed that mainly fatty acids and glycerophospholipids were the most abundant classes of lipids in the MS signature (Table 2). The AUC for the MS signature was 0.702 (0.458-0.981) and the p-value for the permutation test was 0.08 (Figure $2 \mathrm{~B}$ and $2 \mathrm{C}$ ).

\section{CSF - MS versus OIND}

After evaluating the different profiles of inflammatory versus noninflammatory diseases, and the presence of an MS pattern, we searched for a specific cluster that would better distinguish MS from other inflammatory neurological diseases. 
Table 2. Lipids associated with multiple sclerosis in CSF and Plasma

\begin{tabular}{|c|c|c|c|c|c|c|}
\hline Variable & Input Mass & Matched Mass & Delta $\mathrm{m} / \mathrm{z}$ & Formula & Ion & Name \\
\hline \multicolumn{7}{|c|}{ CSF INF x NINF } \\
\hline & 6.183 .572 & 6.183 .976 & 0.0404 & $\mathrm{C} 33 \mathrm{H} 57 \mathrm{NO} 08 \mathrm{Na}$ & {$[\mathrm{M}+\mathrm{Na}]+$} & Sterol Lipid \\
\hline & 6.183 .572 & 6.183 .168 & 0.0404 & C28H54NO9PK & {$[\mathrm{M}+\mathrm{K}]+$} & Glycerophospolipid \\
\hline & 29.516 .225 & 2.951 .329 & 0.0294 & $\mathrm{C} 19 \mathrm{H} 1903$ & {$[\mathrm{M}+\mathrm{H}-\mathrm{H} 2 \mathrm{O}]+$} & Polyketide \\
\hline & 29.516 .225 & 2.951 .904 & 0.0281 & $\mathrm{C} 17 \mathrm{H} 2704$ & {$[\mathrm{M}+\mathrm{H}-\mathrm{H} 2 \mathrm{O}]+$} & Fatty Acid \\
\hline & 29.516 .225 & 2.952 .056 & 0.0434 & $\mathrm{C} 21 \mathrm{H} 270$ & {$[\mathrm{M}+\mathrm{H}-\mathrm{H} 2 \mathrm{O}]+$} & Sterol Lipid \\
\hline & 64.031 .395 & 6.403 .116 & 0.0023 & C35H46N010 & {$[\mathrm{M}+\mathrm{H}]+$} & Polyketide \\
\hline & 66.916 .645 & 6.691 .298 & 0.0367 & $\mathrm{C} 28 \mathrm{H} 29019$ & {$[\mathrm{M}+\mathrm{H}]+$} & Polyketide \\
\hline
\end{tabular}

CSF MSXIH

$\begin{array}{cccccc}29.516 .225 & 2.952 .034 & .0411 & \mathrm{C} 16 \mathrm{H} 32 \mathrm{O} 2 \mathrm{~K} & {[\mathrm{M}+\mathrm{K}]+} & \text { Fatty esters } \\ 29.516 .225 & 2.951 .644 & .0022 & \mathrm{C} 16 \mathrm{H} 2602 \mathrm{Na} 2 & {[\mathrm{M}+2 \mathrm{Na}-\mathrm{H}]+} & \text { Fatty esters } \\ 438.178 & 4.381 .887 & .0107 & \mathrm{C} 18 \mathrm{H} 34 \mathrm{NO10P} & {[\mathrm{M}+\mathrm{H}-\mathrm{H} 2 \mathrm{O}]+} & \text { Glycerophosphoserines } \\ 910.514 & 910.648 & .0134 & \mathrm{C} 11 \mathrm{H} 1602 & {[\mathrm{M}+2 \mathrm{H}] 2+} & \text { Fatty esters } \\ 3.202 .338 & 3.202 .152 & .0186 & \mathrm{C} 32 \mathrm{H} 63010 \mathrm{P} & {[\mathrm{M}+2 \mathrm{H}] 2+} & \text { Glycerophosphoglycerols } \\ 3.202 .338 & 3.202 .528 & .0190 & \mathrm{C} 41 \mathrm{H} 6605 & {[\mathrm{M}+2 \mathrm{H}] 2+} & \text { Diradylglycerols } \\ 3.202 .338 & 3.202 .504 & .0166 & \mathrm{C} 37 \mathrm{H} 7005 \mathrm{Na} 2 & {[\mathrm{M}+2 \mathrm{Na}] 2+} & \text { Diradylglycerols } \\ 3.202 .338 & 3.202 .580 & .0242 & \mathrm{C} 41 \mathrm{H} 7002 \mathrm{Na} 2 & {[\mathrm{M}+2 \mathrm{Na}] 2+} & \text { Sterols }\end{array}$

\begin{tabular}{|c|c|c|c|c|c|c|}
\hline & 755.363 & 7.553 .613 & 0.0017 & $\mathrm{C} 34 \mathrm{H} 60016 \mathrm{P}$ & {$[\mathrm{M}+\mathrm{H}-\mathrm{H} 2 \mathrm{O}]+$} & Glycerophospolipid \\
\hline & 755.363 & 7.553 .613 & 0.0348 & C37H64013K & {$[\mathrm{M}+\mathrm{K}]+$} & Sterol lipid \\
\hline & 2.941 .781 & 2.942 .064 & 0.0283 & $\mathrm{C} 17 \mathrm{H} 28 \mathrm{NO} 3$ & {$[\mathrm{M}+\mathrm{H}-\mathrm{H} 2 \mathrm{O}]+$} & Fatty Acid \\
\hline & 3.881 .859 & 3.882 .223 & 0.0364 & C17H36N05PNa & {$[\mathrm{M}+\mathrm{Na}]+$} & Sphingolipid \\
\hline & 3.881 .958 & 3.882 .223 & 0.0265 & C17H36N05PNa & {$[\mathrm{M}+\mathrm{Na}]+$} & Sphingolipid \\
\hline & 3.881 .958 & 3.882 .412 & 0.0454 & $\mathrm{C} 22 \mathrm{H} 360 \mathrm{~K} 1 \mathrm{~F}$ & {$[\mathrm{M}+\mathrm{K}]+$} & Fatty Acid \\
\hline \multirow[t]{11}{*}{ PLASMA MS X OIND } & 8.015 .357 & 8.015 .429 & 0.0072 & C47H7808P & {$[\mathrm{M}+\mathrm{H}]+$} & Glycerophospholipid \\
\hline & 8.015 .357 & 8.015 .723 & 0.0366 & C44H81012 & {$[\mathrm{M}+\mathrm{H}-\mathrm{H} 2 \mathrm{O}]+$} & Saccharolipids \\
\hline & 8.015 .357 & 8.015 .723 & 0.0366 & C44H81012 & {$[\mathrm{M}+\mathrm{H}-\mathrm{H} 2 \mathrm{O}]+$} & Fatty Acid \\
\hline & 8.015 .357 & 8.015 .487 & 0.013 & $\mathrm{C} 45 \mathrm{H} 78010 \mathrm{Na}$ & {$[\mathrm{M}+\mathrm{Na}]+$} & Glycerolipid \\
\hline & 8.513 .786 & 851.419 & 0.0404 & $\mathrm{C} 42 \mathrm{H} 68015 \mathrm{~K}$ & {$[\mathrm{M}+\mathrm{K}]+$} & Prenol Lipid \\
\hline & 55.324 .565 & 5.532 .136 & 0.0321 & $\mathrm{C} 24 \mathrm{H} 41010 \mathrm{~S} 2$ & {$[\mathrm{M}+\mathrm{H}]+$} & Sterol Lipid \\
\hline & 55.324 .565 & 5.532 .585 & 0.0128 & С35H3706 & {$[\mathrm{M}+\mathrm{H}-\mathrm{H} 2 \mathrm{O}]+$} & Polyketide \\
\hline & 55.324 .565 & 5.532 .772 & 0.0316 & $\mathrm{C} 25 \mathrm{H} 46011 \mathrm{P}$ & {$[\mathrm{M}+\mathrm{H}-\mathrm{H} 2 \mathrm{O}]+$} & Glycerophospholipid \\
\hline & 55.324 .565 & 5.532 .344 & 0.0112 & C25H42N2O7SK & {$[\mathrm{M}+\mathrm{K}]+$} & Fatty Acid \\
\hline & 55.324 .565 & 5.532 .562 & 0.0106 & $\mathrm{C} 30 \mathrm{H} 42 \mathrm{O} \mathrm{K}$ & {$[\mathrm{M}+\mathrm{K}]+$} & Prenol Lipid \\
\hline & 7.783 .713 & 7.784 .056 & 0.0343 & С39H66N010PK & {$[\mathrm{M}+\mathrm{K}]+$} & Glycerophospholipid \\
\hline
\end{tabular}

CSF- Cerebrospinal fluid INF- Inflammatory group; N_INF - Noninflammatory group; IIH - Idiopathic intracranial hypertension; MS - multiple sclerosis; OIND - Other inflammatory neurological diseases.

The PLS-DA analysis suggested that component 4 of this model was the one that best explained the variations of ions between the groups. Figure 3A shows the group of
15 VIP ions with the greatest discriminatory PLS-DA score. Lipid identification revealed that fatty acids and sphingolipids were the most abundant classes of lipids in the MS 

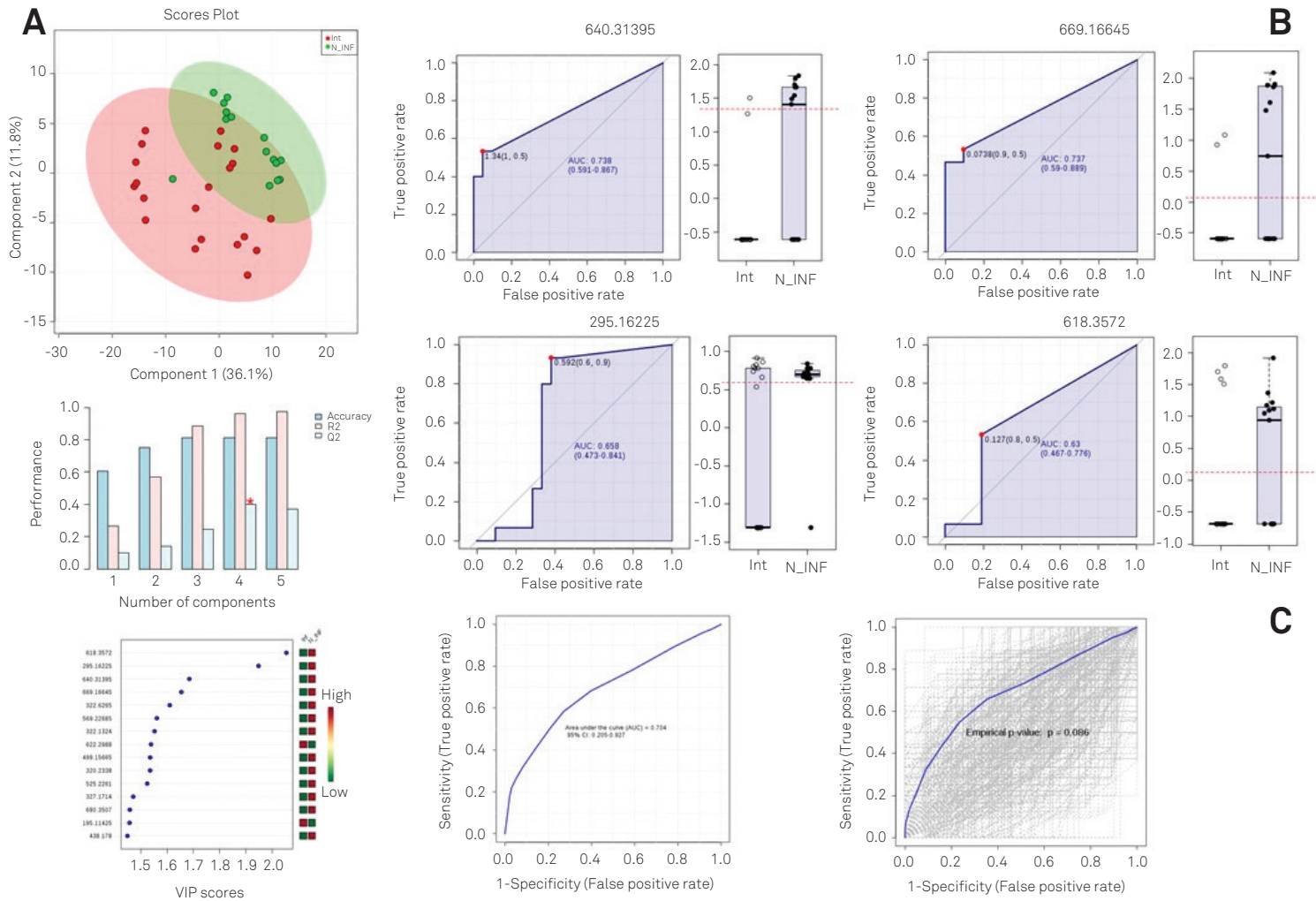

C

Figure 1. A. PLS-DA analysis comparing CSF of inflammation versus noninflammation (multiple sclerosis and other inflammatory diseases versus idiopathic intracranial hypertension) showing component 4 as the most discriminatory between the groups, and the VIP ions with the higher scores. B. ROC curves for each of the four VIP ions with the higher score. C. ROC curve and the permutation test for the CSF inflammatory signature considering the four ions with the highest scores.
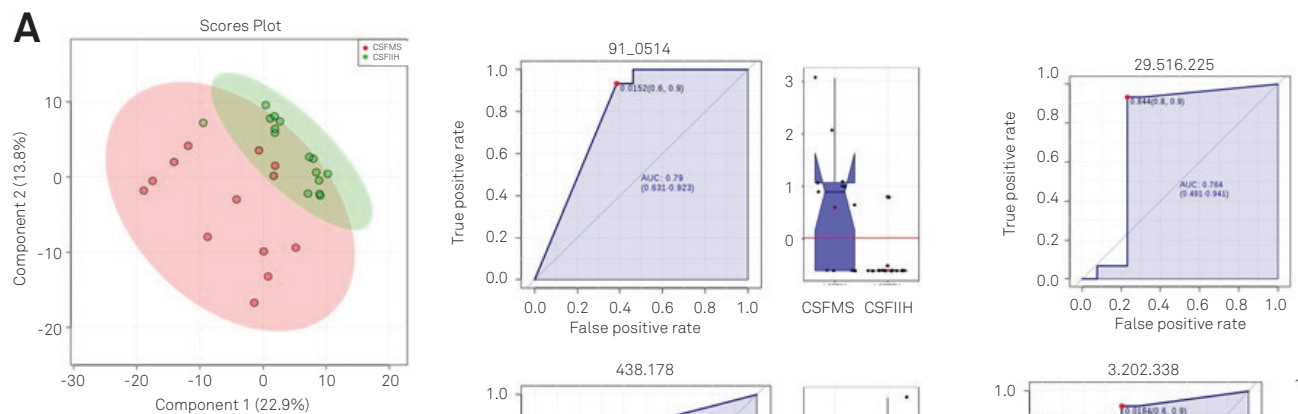

B
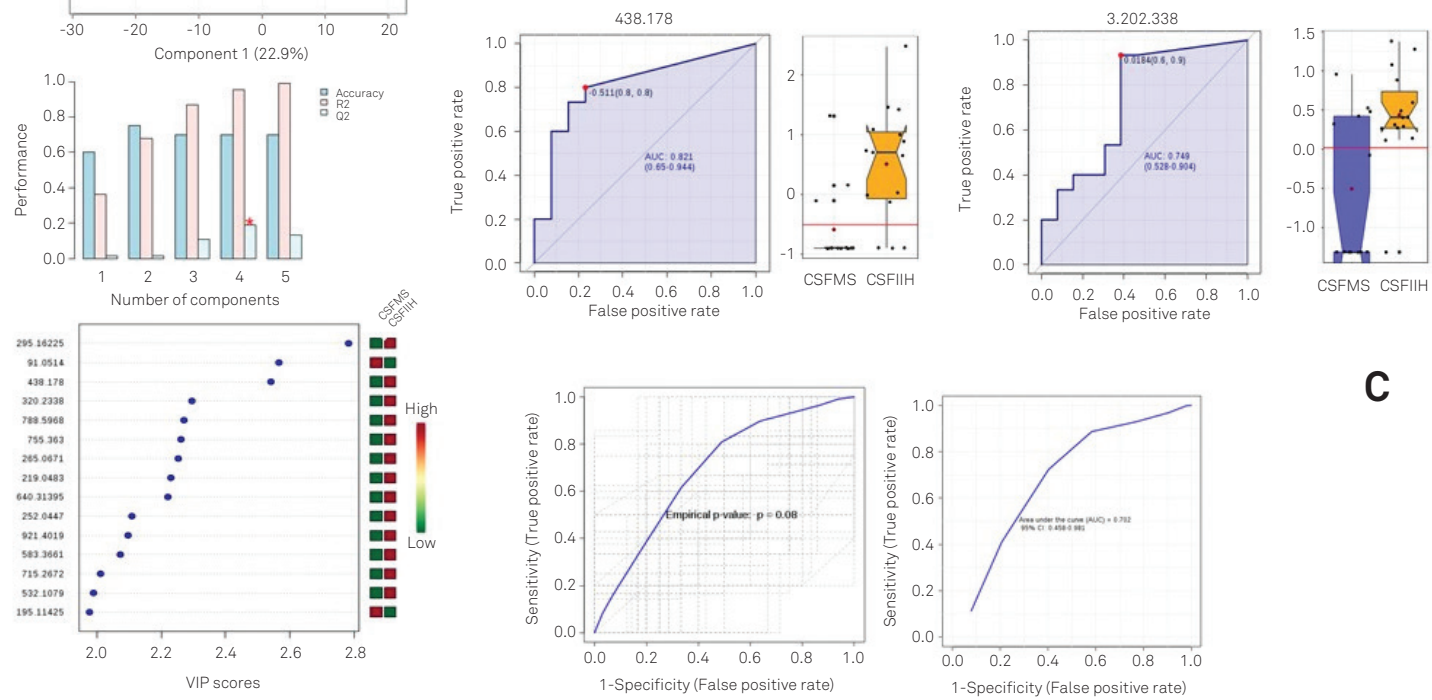

C

Figure 2. A. PLS-DA analysis comparing CSF of multiple sclerosis versus idiopathic intracranial hypertension showing component 4 as the most discriminatory between the groups and the VIP ions with the higher scores. B. ROC curves for each of the four VIP ions with the higher score. C. ROC curve and the permutation test for the MS-CSF lipid signature considering the four ions with the highest scores. 

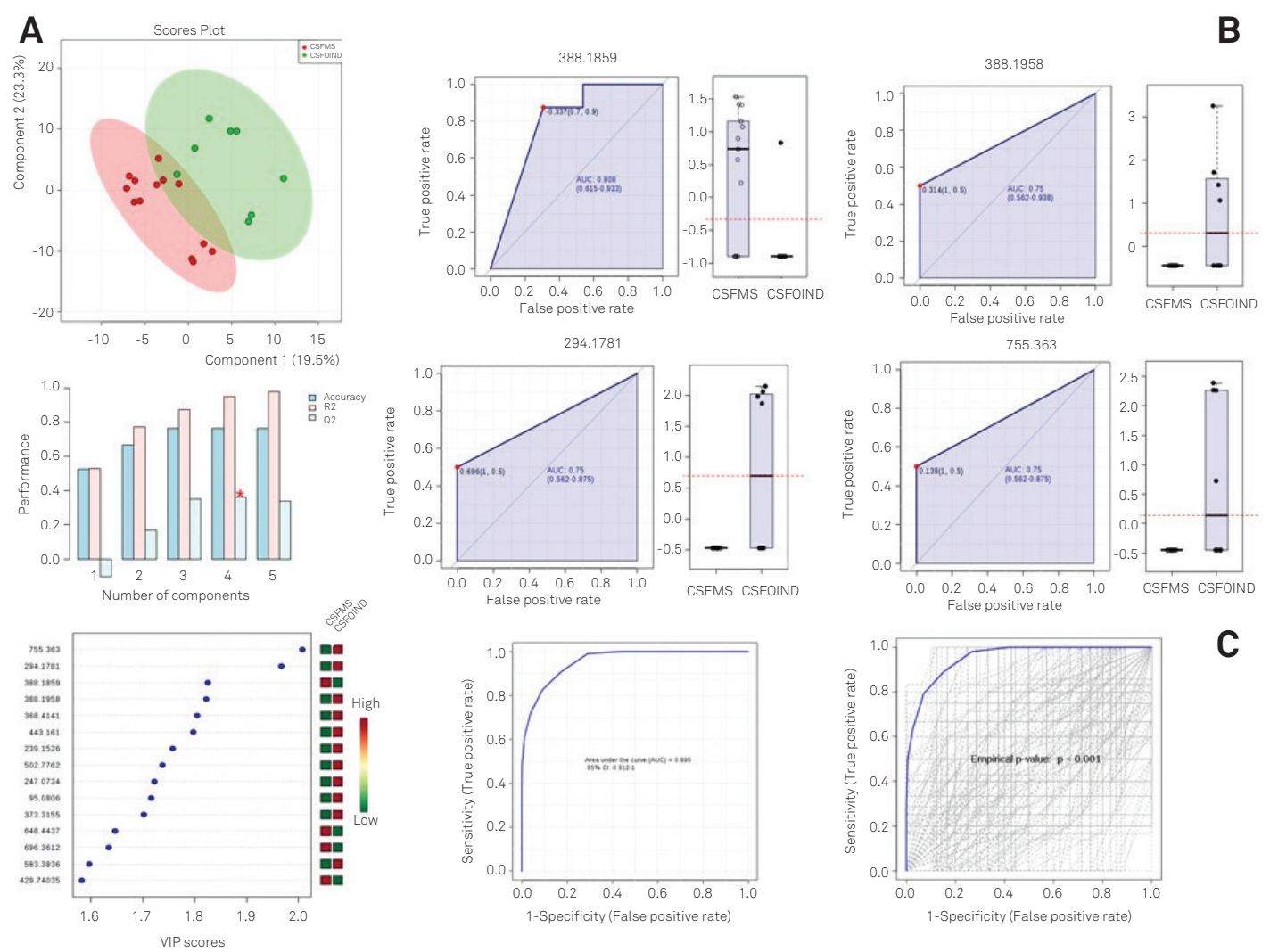

C

Figure 3. A. PLS-DA analysis comparing CSF of patients with MS versus other inflammatory neurological diseases showing component 4 as the most discriminatory between the groups and the VIP ions with the higher scores. B. ROC curves for each of the four VIP ions with the higher score. C. ROC curve and the permutation test for the MS-CSF lipid signature considering the four ions with the highest scores.
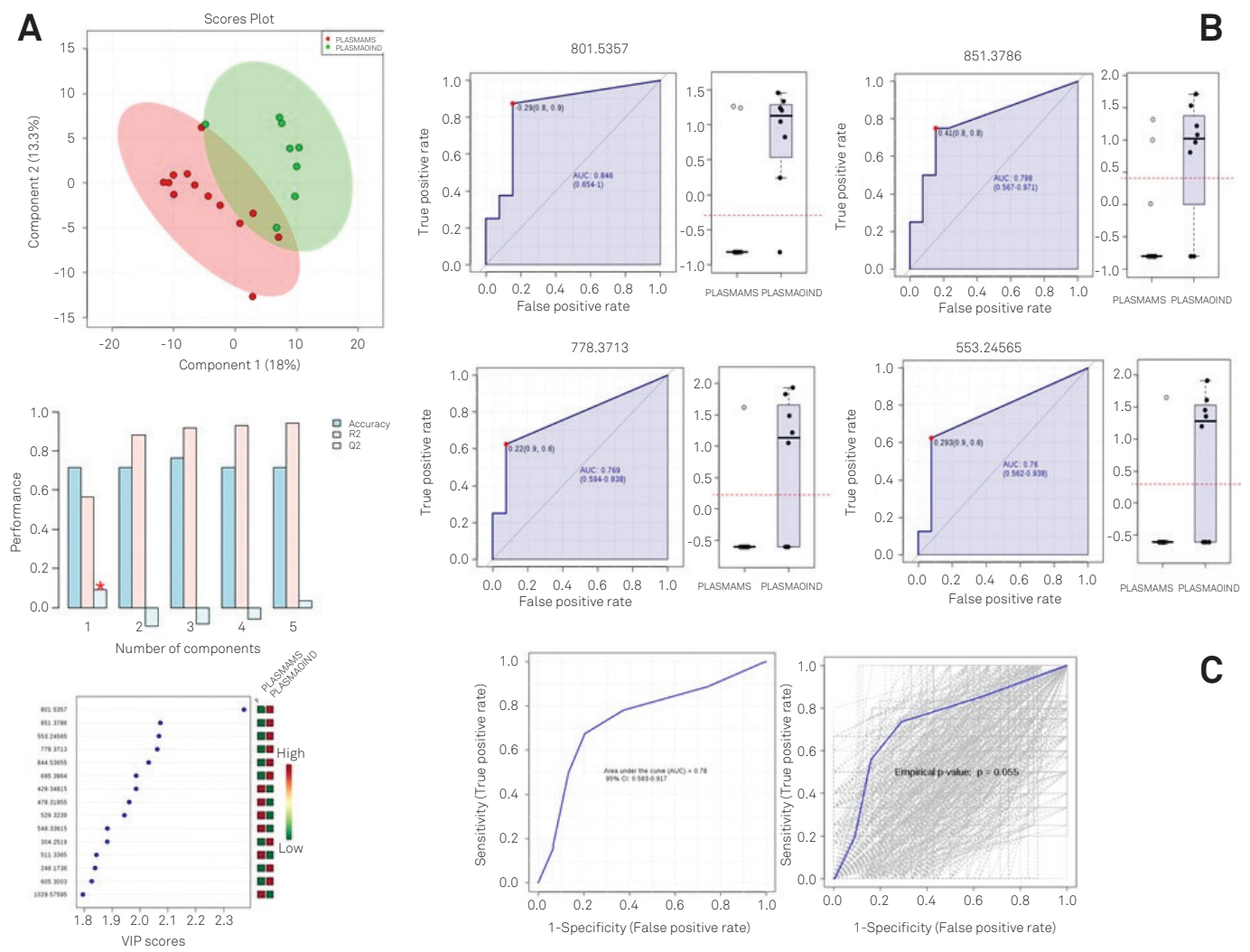

C

Figure 4. A. PLS-DA analysis comparing plasma of patients with MS versus other inflammatory neurological diseases showing component 1 as the most discriminatory between the groups and the VIP ions with the higher scores. B. ROC curves for each of the four VIP ions with the higher score. C. ROC curve and the permutation test for the MS-plasma lipid signature considering the four ions with the highest scores. 
signature (Table 2). The AUC for the MS signature was 0.995 $(0.912-1)$ and the $p$-value for the permutation test was $<0.001$, indicating that this ion combination is useful for the MS diagnosis (Figure 3B and 3C).

\section{Plasma - MS versus OIND}

We hypothesized that the inflammatory process observed in the CSF of patients with MS would be reflected in the plasma and that it could be useful in differentiating MS from OIND. Therefore, we performed a lipidomics analysis of 21 plasma samples collected together with the paired CSF samples.

The PLS-DA analysis showed that component 1 of this model was the one that best explained the variations of ions between the groups. Figure 4A shows the group of 15 VIP ions with the greatest discriminatory PLS score. Lipid identification revealed that glycerolipids and fatty acids were the main class of lipids in the plasma MS signature (Table 2). The AUC for the MS signature was 0.78 (0.5830.917 ) and the p-value for the permutation test was 0.055 (Figure 4B and 4C)

\section{DISCUSSION}

Our results suggest that it is possible to separate patients with MS from OIND based on the lipid profile present in the CSF and plasma. Particularly, in the CSF, the ions had a predictive value of $99 \%$ to discriminate patients with MS from patients with OIND. It is interesting to highlight that the lipid profile we obtained from plasma, although discriminatory, showed marginal significance.

Multiple sclerosis and OIND had some degree of inflammation, but it was more pronounced in the latter. Patients in the OIND group had a higher lymphocyte count and a higher level of protein. Curiously, we cannot say that we found an "inflammatory" signature, as the comparison between the inflammation versus the noninflammation groups, although showing some degree of separation, did not reach statistical significance. Based on the routine CSF analysis, the IIH group did not show any signs of ongoing inflammation, contrasting with the patients with MS and OIND and, despite this, the separation between groups was not clear. The etiology of IIH remains elusive, and one could speculate whether these patients should have been used as our control group.

The identification of the lipids in plasma and CSF showed a mixture of classes from fatty acids to polyketides. Of interest, we emphasize the presence of glycerolipids and sphingolipids in the CSF of patients with MS. Both classes are involved in cell signaling and regulation of biological processes. There is evidence suggesting their role in different diseases such as asthma and breast cancer ${ }^{10}$. In MS, it has been shown that ceramide levels were elevated in MS CSF and this may be sufficient to cause axonal damage ${ }^{12}$. Interestingly, in an animal model of demyelination, the blockade of acid sphingomyelinase improves remyelination, suggesting the importance of the acid sphingomyelinase/ceramide pathway in $\mathrm{MS}^{19}$. Therefore, it is reassuring that on a simple qualitative untargeted analysis, we found the same lipid classes to be discriminative of MS.

The presence of a lipid signature recognizable outside the CNS in patients with MS suggests that the breakdown of the blood-brain barrier is as important as the inflammatory process. The most abundant lipid class we found in plasma from patients with MS were the glycerophospholipids, mirroring what we had found in the CSF. Recent studies have demonstrated that glycerophospholipids are discriminatory between MS and healthy controls. Moreover, these lipids were also linked to a more severe disease $\mathrm{e}^{16,20}$, implying that lipid metabolism may be related to oxidative stress, mitochondrial dysfunction, and degeneration ${ }^{11}$. Thus, the observed lipid profile could mean a degenerative signature rather than an inflammatory one, particularly when one considers that patients with MS, although younger than the control groups, had a longer disease duration and greater neurological disability.

We need to be careful in interpreting these data because the small number of samples may have influenced the results. We did not observe a defined inflammatory pattern, nor did we separate MS from IIH. However, the lack of statistical significance does not mean that there is no biological effect, as we still observed a specific MS signature.

Furthermore, the comparison between the main demyelinating diseases, MS and neuromyelitis optica was not possible, as the OIND group was very heterogeneous, comprising inflammatory diseases of different etiologies and in limited number. This heterogeneity itself could, in part, explain our results.

In addition, the small number of patients did not allow us to establish differences between the clinical forms of MS, and prevented us from performing analysis of lipid profiles and Expanded Disability Status Scale progression.

Our results may have been influenced by the quality of the material. The samples were frozen for up to two years and it is possible that some degree of molecule degradation occurred, as it has been shown that cycles of freezing and thawing can alter the biochemical analysis. Nevertheless, all samples were submitted to the same extraction protocol, handled in the same way, and were equally affected. Likewise, we acknowledge that high resolution mass spectrometry is useful for identifying biomarkers but as we did not acquire MS/MS spectra, the exact identification of lipids was limited.

Moreover, the presence of polyketides, a lipid species that is foreign to mammalian metabolism might be explained by the immunosuppressants or antibiotics some patients were receiving at the time of the sample collection. Clinical information was gathered in a retrospective manner by review of 
the patients' files and it should always be considered a potential source of bias.

Our results should be viewed as a first step towards the identification of pathways and molecules that could be useful as diagnostic biomarkers in Brazilian patients. Also, it reinforces the need for quantitative analyses to further investigate the role of complex lipids in the pathogenesis of MS.

We observed a distinctive lipid signature in the CSF and plasma from patients with MS that may be used as a diagnostic biomarker. Understanding MS at the molecular level may be challenging but it is essential for drug development and patient care.

\section{Acknowledgments}

The authors thank Senne Liquor Diagnóstico for technical support and sample storage. This study was financed in part by the Coordenação de Aperfeiçoamento de Pessoal de Nível Superior - Brasil (CAPES) - Finance Code 001 (A.F.R.O and D.A.M.).

\section{References}

1. Kamm CP, Uitdehaag BM, Polman CH. Multiple sclerosis: current knowledge and future outlook. Eur Neurol. 2014;72(3-4):132-41. https://doi.org/10.1159/000360528

2. Polman $\mathrm{CH}$, Reingold SC, Banwell B, Clanet M, Cohen JA, Filippi $M$, et al. Diagnostic criteria for multiple sclerosis: 2010 revisions to the McDonald criteria. Ann Neurol. 2011 Feb;69(2):292-302. https://doi.org/10.1002/ana.22366.

3. Fitzner B, Hecker M, Zettl UK. Molecular biomarkers in cerebrospinal fluid of multiple sclerosis patients. Autoimmun Rev. 2015 Oct;14(10):903-13. https://doi.org/10.1016/j.autrev.2015.06.001

4. Tomioka R, Matsui M. Biomarkers for multiple sclerosis [Internet]. Intern Med. 2014;53(5):361-5. https://doi.org/10.2169/internalmedicine.53.1246

5. Simon MJ, Iliff JJ. Regulation of cerebrospinal fluid (CSF) flow in neurodegenerative, neurovascular and neuroinflammatory disease. Biochim Biophys Acta. 2016 Mar; 1862(3):442-51. https://doi.org/10.1016/j.bbadis.2015.10.014

6. Reinke S, Broadhurst D, Sykes B, Baker G, Catz I, Warren K, et al. Metabolomic profiling in multiple sclerosis: insights into biomarkers and pathogenesis. Mult Scler. 2014 Sep;20(10):1396-400. https://doi.org/10.1177/1352458513516528

7. Hinsinger G, Galéotti N, Nabholz N, Urbach S, Rigau V, Dematte $\mathrm{C}$, et al. Chitinase 3-like proteins as diagnostic and prognostic biomarkers of multiple sclerosis. Mult Scler. 2015 Sep;21(10):125161. https://doi.org/10.1177/1352458514561906

8. Cermenati G, Mitro N, Audano M, Melcangi RC, Crestani M, De Fabiani E, et al. Lipids in the nervous system: from biochemistry and molecular biology to patho-physiology. Biochim Biophys Acta. 2015 Jan;1851(1):51-60. https://doi.org/10.1016/j.bbalip.2014.08.011

9. Adibhatla RM, Hatcher JF. Role of Lipids in Brain Injury and Diseases [Internet]. Future Lipidol. 2007 Aug;2(4):403-22. https://doi.org/10.2217/17460875.2.4.403

10. Balgoma D, Checa A, Sar DG, Snowden S, Wheelock CE. Quantitative metabolic profiling of lipid mediators. Mol Nutr Food Res. 2013 Aug;57(8):1359-77. https://doi.org/10.1002/mnfr.201200840

11. Gonzalo H, Brieva L, Tatzber F, Jové M, Cacabelos D, Cassanyé A, et al. Lipidome analysis in multiple sclerosis reveals protein lipoxidative damage as a potential pathogenic mechanism. J Neurochem. 2012 Nov;123(4):622-34. https://doi.org/10.1111/j.1471-4159.2012.07934.x
12. Vidaurre OG, Haines JD, Katz Sand I, Adula KP, Huynh JL, McGraw $\mathrm{CA}$, et al. Cerebrospinal fluid ceramides from patients with multiple sclerosis impair neuronal bioenergetics. Brain. 2014 Aug;137(Pt 8):2271-86. https://doi.org/10.1093/brain/awu139

13. Pieragostino D, Cicalini I, Lanuti P, Ercolino E, di loia M, Zucchelli M, et al. Enhanced release of acid sphingomyelinaseenriched exosomes generates a lipidomics signature in CSF of Multiple Sclerosis patients. Sci Rep. 2018 Feb;8(1):3071. https://doi.org/10.1038/s41598-018-21497-5

14. Poddighe S, Murgia F, Lorefice L, Liggi S, Cocco E, Marrosu MG, et al. Metabolomic analysis identifies altered metabolic pathways in Multiple Sclerosis [Internet]. Int J Biochem Cell Biol. 2017 Dec;93:148-55. https://doi.org/10.1016/j.biocel.2017.07.004

15. Cocco E, Murgia F, Lorefice L, Barberini L, Poddighe S, Frau J, et al. $1 \mathrm{H}-\mathrm{NMR}$ analysis provides a metabolomic profile of patients with multiple sclerosis. Neurol - Neuroimmunol Neuroinflammation. 2016;3(1):1-10. https://doi.org/10.1212/NXI.0000000000000185

16. Villoslada P, Alonso C, Agirrezabal I, Kotelnikova E, Zubizarreta I, Pulido-Valdeolivas I, et al. Metabolomic signatures associated with disease severity in multiple sclerosis. Neurol Neuroimmunol Neurolnflammation. 2017;4(2). https://doi.org/10.1212/NXI.0000000000000321

17. Bhargava P, Fitzgerald KC, Calabresi PA, Mowry EM. Metabolic alterations in multiple sclerosis and the impact of vitamin D supplementation [Internet]. JCI Insight. 2017 Oct;2(19):1-13. https://doi.org/10.1172/jci.insight.95302

18. Bligh EG, Dyer WJ. A rapid method of total lipid extraction and purification. Can J Biochem Physiol. 1959 Aug;37(8):911-7. https://doi.org/10.1139/059-099

19. Chami M, Halmer R, Schnoeder L, Anne Becker K, Meier C, Fassbender K, et al. Acid sphingomyelinase deficiency enhances myelin repair after acute and chronic demyelination. PLoS One. 2017 Jun;12(6):e0178622. https://doi.org/10.1371/journal.pone.0178622

20. Del Boccio P, Pieragostino D, Di loia M, Petrucci F, Lugaresi A, De Luca G, et al. Lipidomic investigations for the characterization of circulating serum lipids in multiple sclerosis. J Proteomics. 2011 Nov;74(12):2826-36. https://doi.org/10.1016/j.jprot.2011.06.023 